\title{
Mother and Infant Nutrition Investigation in New Zealand (MINI Project): Protocol for an Observational Longitudinal Cohort Study
}

Ying Jin ${ }^{1}$, BSc, MSc; Jane Coad ${ }^{2}$, BSc, PhD; Shao J Zhou ${ }^{3}$, BSc, MSc, PhD; Sheila Skeaff ${ }^{4}, \mathrm{MSc}$, PhD; Cheryl Benn ${ }^{5}$, BSocSc, MCur (Midwifery), PhD; Nicholas Kim ${ }^{6}, \mathrm{BSc}, \mathrm{PhD}$; Rachael L Pond ${ }^{7}, \mathrm{BSc}, \mathrm{PhD}$; Louise Brough ${ }^{2}, \mathrm{BSc}$ $\mathrm{MSc}, \mathrm{PhD}$

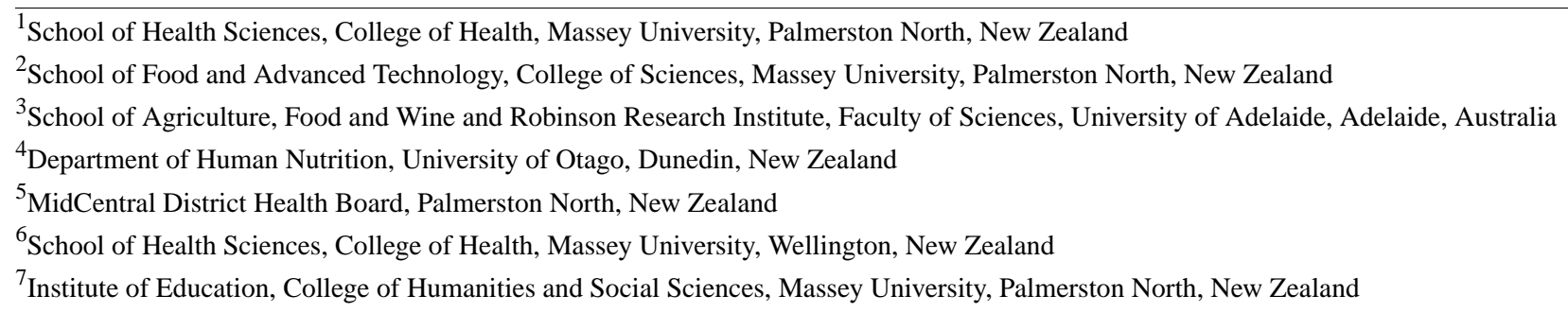

Corresponding Author:

Louise Brough, BSc, MSc, PhD

School of Food and Advanced Technology

College of Sciences

Massey University

Riddet Complex

Palmerston North

New Zealand

Phone: 6469517575

Email: 1.brough@massey.ac.nz

\section{Abstract}

Background: Thyroid dysfunction is associated with cognitive impairment, mood disturbance, and postnatal depression. Sufficient thyroid hormone synthesis requires adequate intake of iodine, selenium, and iron. Iodine deficiency was historically a problem for New Zealand, and initiatives were introduced to overcome the problem: (1) mandatory fortification of all bread (except organic) with iodized salt (2009) and (2) provision of subsidized iodine supplements for pregnant and breastfeeding women (2010). Subsequent to these initiatives, most adults and children have adequate iodine status; however, status among breastfeeding women and their infants remains unclear. This paper outlines the methodology of the Mother and Infant Nutrition Investigation (MINI) study: an observational longitudinal cohort study of breastfeeding women and their infants.

Objective: This study will determine (1) women's iodine intake and status among supplement users and nonusers; (2) women's intake and status of iodine, selenium, and iron relating to thyroid function; (3) associations between women's selenium status, thyroid function, and postnatal depression; (4) infants' iodine and selenium status relating to first year neurodevelopment.

Methods: Breastfeeding women aged over 16 years with a healthy term singleton infant were recruited from Manawatu, New Zealand. Participants attended study visits 3, 6, and 12 months postpartum. Maternal questionnaires investigated supplement use before and after birth, iodine knowledge, and demographic information. Dietary assessment and urine, blood, and breast milk samples were taken to measure iodine, selenium, and iron intake/status. The Edinburgh Postnatal Depression Scale was used repeatedly to screen for postnatal depression. Thyroid hormones (free triiodothyronine, free thyroxine, thyroid stimulating hormone, thyroglobulin, antithyroglobulin antibodies, and antithyroid peroxidase) were measured in blood samples, and thyroid gland volume was measured by ultrasound at 6 months postpartum. Infant iodine and selenium concentrations were determined in urine. The Ages and Stages Questionnaire was used to assess infant development at 4, 8, and 12 months.

Results: Data collection was completed. Biological samples analysis, excluding nail clippings, is complete. Data analysis and presentation of the results will be available after 2020 .

Conclusions: This study will provide data on the current iodine status of breastfeeding women. It will also provide a greater understanding of the three essential minerals required for optimal thyroid function among breastfeeding women. The prospective 
longitudinal design allows opportunities to examine women's mental health and infant neurodevelopment throughout the first year, a crucial time for both mothers and their infants.

Trial Registration: Australian New Zealand Clinical Trials Registry ACTRN12615001028594; https://www.anzctr.org.au/Trial/Registration/TrialReview.aspx?id=369324

International Registered Report Identifier (IRRID): DERR1-10.2196/18560

(JMIR Res Protoc 2020;9(8):e18560) doi: 10.2196/18560

\section{KEYWORDS}

iodine; selenium; iron; thyroid hormone; breastfeeding women; postnatal depression; infant neurodevelopment; thyroid; maternal health; nutrition

\section{Introduction}

\section{Background}

Postpartum women experience abnormalities in thyroid function at twice the prevalence of the general population [1]. Thyroid hormone is essential in maintaining the human body's metabolism, temperature (thermoregulation), and psychological mood [2]. In a developing brain, thyroid hormone is responsible for adequate myelination, neuron cell maturation, and central nervous system development [3]. Optimal thyroid function relies on adequate biosynthesis of thyroid hormones, which depends on three dietary minerals: iodine, selenium, and iron [4,5]. Pregnancy increases thyroid hormone turnover; thus, women with limited thyroidal reserve or marginal iodine deficiency are at increased risk to develop thyroid dysfunction after birth [6] This is one of the most common endocrine disorders that postpartum women experience [7].

Iodine is the major component of thyroid hormones, but it is also a regulator for the synthesis and secretion of the thyroid hormones triiodothyronine (T3) and thyroxine (T4). Selenium, as a component of the selenocysteine-containing proteins glutathione peroxidase, protects the thyroid gland from oxidative damage [5]. Selenoproteins are required to convert T4 to T3, the active form of thyroid hormone. Iron is required for heme-dependent thyroperoxidase activity, which is required for the synthesis of adequate thyroid hormone. Selenium deficiency and iron deficiency anemia may negatively affect thyroid hormone synthesis by impairing selenium- and iron-dependent enzyme activities, even if iodine status is adequate [5]. Most previous research has investigated iodine, selenium, and iron intake/status separately or a combination of any two of them among women of childbearing age [8] and postmenopausal women [9]. However, further research is needed to explore all three micronutrients together, acknowledging their close relationship in thyroid hormone synthesis.

Thyroid dysfunction is a significant health issue in New Zealand, with women diagnosed at 5 times the prevalence in men [10,11]. Concerning adequate thyroid function, iodine, selenium, and iron play important roles. In New Zealand, soils provide low levels of available iodine and selenium, resulting in low concentrations in the food supply [12], hence in the diet [13]. Iodine deficiency in early life is associated with impaired neurodevelopment [14]. Iodine deficiency was a concern in New Zealand in the early years of the 20th century, but its prevalence was mostly reduced through the introduction of iodized salt in the 1930s. However, since the 1990s, a number of studies in New Zealand have shown iodine deficiency has reemerged in adults [15], pregnant and breastfeeding women $[16,17]$, school children [18] and breastfed infants and toddlers [19]. To improve iodine status in New Zealand, two government initiatives were introduced: mandatory iodized salt in commercially made bread products from September 2009 and the provision of iodine supplementation for all pregnant and lactating women in 2010 [20]. Although recent studies suggested that adults [21,22] and children [23] in New Zealand may now have adequate iodine intake/status, both pregnant and breastfeeding women remain deficient. A pilot study of a small sample of self-selected highly educated pregnant and breastfeeding women assessed urinary iodine excretion, breast milk iodine concentration, and blood thyroglobulin and suggested iodine deficiency [24]. There is a need for a more robust investigation into the iodine status of postpartum women and their infants from a wide range of socioeconomic backgrounds.

Low selenium status in New Zealand has been partially reversed by increased consumption of imported flour from Australia (which generally has higher selenium concentrations than flour produced in New Zealand) $[25,26]$. In addition, both pregnant and breastfeeding women have an increased requirement for dietary selenium due to the demands from the fetus and breastfed infants. Previous research, which investigated selenium status among postpartum women and their infants in New Zealand 20 years ago [27], measured urinary selenium excretion and plasma selenium and indicated that such women were at risk of selenium deficiency. To our knowledge only one small study of breastfeeding women, by our research group, assessed dietary selenium, urinary selenium excretion, and breast milk selenium concentration and suggested selenium inadequacy was still a concern [28]. There remains a lack of research investigating selenium status among postpartum women and their infants.

Health professionals closely monitor the iron status of women during pregnancy. However, after birth, management of iron status can be inconsistent. Results from a UK multicenter study reported only $50 \%$ of postpartum women had hemoglobin levels checked after delivery (with $30 \%$ of those women confirmed as anemic), while the overall iron stores of participating women remained unexamined [29]. Generally, postpartum women's iron status recovers as a consequence of cessation of menstrual bleeding since conception or a minimal secretion of iron via breast milk if breastfeeding [30]. However, if women have suffered iron deficiency before and/or during pregnancy and/or 
have experienced significant blood loss during the birth, their iron status may not reach optimal levels even if an intervention subsequently occurs. A New Zealand study of 186 women found $77 \%$ of women were not tested for hemoglobin levels after birth. Further, out of those most at risk (with low iron status during late pregnancy and high blood loss, exceeding $500 \mathrm{~mL}$, during birth), few women were then retested for their iron status after 10 days postpartum [31]. Iron status of postpartum women remains largely underreported.

Moreover, low serum selenium has been identified as an independent risk factor for depression, [32] and selenium supplementation has been observed to reduce postnatal depression [33]. Postnatal depression is one of the main disorders women experience postnatally, its onset being timed at 6 weeks to 6 months after birth. Most women will recover from postpartum depression, though approximately one-quarter of affected women report being depressed when their infant reaches their first birthday [34]. Using the measured criteria of postnatal depression on the Edinburgh Postnatal Depression Scale (EPDS), the prevalence of postnatal depression in New Zealand was about $8 \%$ in 1994 and $16 \%$ in 2006 . In the 2015 New Mothers' Mental Health Survey [35], the prevalence was $14 \%$ and is now recorded as the most common disorder for mothers in their first year after childbirth [36].

Of additional concern, mothers are often reluctant or unable to seek help when they experience symptoms of postnatal depression [35]. Such underdiagnosed and untreated mental health conditions affect both the mother and their children's ongoing cognitive, emotional, and behavioral development [37]. Despite other social and psychological etiology of depression, potential links between micronutrient status, thyroid hormone, and the risk of postpartum depression need to be further explored. This may help develop new preventive approaches to lowering the risks of postpartum depression.

\section{Study Objectives}

The study's primary outcomes include (1) investigating breastfeeding women's iodine intake and status among supplement users and nonusers following the implementation of two government initiatives to improve iodine status; (2) examining maternal iodine, selenium, and iron intake status; and (3) exploring iodine, selenium, and iron status in maternal thyroid function.

In addition, the study provides preliminary data on possible associations between women's selenium status, thyroid function, and postnatal depression over a 1-year period and infants' iodine and selenium status in relation to neurodevelopment during their first year of life. Ultimately, this research will inform a future larger study of potential variables impacting maternal thyroid function and the risk of postnatal depression, together with early infant neurodevelopment.

\section{Methods}

\section{Study Design and Overview}

The Mother and Infant Nutrition Investigation (MINI) study is an observational longitudinal cohort study spanning the first year postpartum. It was approved by the Health and Disability
Ethics Committee (15/NTA/172) in December 2015. The study's ethics approval was registered with the Royal New Zealand Plunket Ethics Committee in June 2016. The MidCentral District Health Board in New Zealand also approved the study. The study was registered with the Australian New Zealand Clinical Trials Registry [ACTRN12615001028594].

The study is being conducted in the Human Nutrition Research Unit at Massey University, Palmerston North, New Zealand. The first study visit for participants is at approximately 3 months postpartum, and follow-up assessments take place at 6 months and 12 months postpartum (Multimedia Appendix 1).

\section{Selection Criteria}

The target population for the study was healthy breastfeeding women aged over 16 years who had birthed a healthy term singleton infant 3 months prior. Women were excluded if they developed significant health problems, such as metabolic disease or cancer. Women were excluded if they had been diagnosed or treated at any time for hyperthyroidism or hypothyroidism. Participants were required to live within or near the local Palmerston North area and be able to attend Massey University for scheduled study visits. Women of any ethnic and socioeconomic status were eligible.

\section{Recruitment and Participation}

Posters to promote the study were placed at selected sites (general practitioner surgeries, midwifery clinics, pharmacies, antenatal classes, ultrasound clinics, maternal wards in hospitals, local community playgroups, and early childhood centers, etc). Local newspapers and social media sites were used to publicize the study. Local midwives, childbirth educators, and lactation consultants were asked to raise awareness of the MINI study to their clients. An effort was made to recruit women from a wide range of socioeconomic backgrounds and ethnic groups, including Maori, Pacific Islanders, and Asian women. Potential participants responded by recording an expression of interest online or via telephone or email. Prospective participants were provided with a study information sheet. Interested participants then completed a screening questionnaire to ensure eligibility. Written informed consent was obtained from all participants before their enrollment in the study. Mothers also gave written consent to their infants' participation in the study. After providing informed consent, participants were assigned a unique identifier code and scheduled for their first study visit.

\section{Sample Size Calculation}

The main outcome measure was iodine excreted per day, and the sample size was calculated using G*Power 3.1 (Heinrich Heine University) based on data (mean and standard deviation) from a preliminary study of breastfeeding women [24]. Calculation used 1-way analysis of variance with two groups (95\% power, =.05, 2-tailed) and three repeat measures; 80 participants were needed, using expected mean daily urine iodine concentrations of 140 and $100 \mu \mathrm{g} / \mathrm{d}$ for iodine supplement users and nonusers, respectively, and a standard deviation of 60 . 


\section{Outcome Measures}

\section{Questionnaires}

At the initial visit, general baseline questions were asked about salt and supplements use, nutrition knowledge of iodine, tobacco and alcohol use, breastfeeding patterns, general health, and demographic information (including age, ethnicity, educational attainment, household size, and income). Potential changeable information including tobacco and alcohol use, breastfeeding patterns, and general health was also sought at the second and third visits.

Participants were assessed about their general health and that of their infants by online questionnaire when infants reached 6 months and 12 months of age. During the postpartum period, stress may negatively affect immunity, and the occurrence of infection symptoms can be an estimated measurement of postpartum immune function. The Carr Infection Symptom Checklist, which has been validated for use with postpartum women [38], was used to measure the symptoms of infection experienced by the mother since the birth. The Infant Symptom Checklist (which reports the frequency of symptoms of common illnesses in young infants) was used to measure the health of infants [38].

The 10-item EPDS was completed online by participating women to assess any symptoms of depression and anxiety over the previous 7 days. Women recorded severity of symptoms on a 4-point scale [39]. Specified anxiety disorders were evaluated using the EPDS-3A, a cluster of selected question items numbered 3, 4, and 5 from the original EPDS [40]. This is a validated tool to screen for probable anxiety and depression during the postpartum period. A cutoff point of 13 or above was used to define high levels of depressive symptoms [35]. Any woman whose score equaled 13 or above was advised to see her general practitioner for further evaluation as well as being provided with an information sheet containing postnatal depression services in New Zealand. Only study participants with the correct link supplied via emails could complete these questionnaires. All questions were answered in the same order. Participants could not go back to change their answers once the questionnaire was completed. Answers from incomplete questionnaires may be used for analysis.

The first year of infant neurodevelopment was assessed using a parent-completed Ages and Stages Questionnaire (ASQ) when the infant was aged 4, 8, and 12 months [41]. These questionnaires were self-administered and completed in hard copies. This screening tool uses parent observation to assess child development and behavior and records results in 5 developmental domains: communication, gross motor, fine motor, problem solving, and personal-social. There are 6 questions in each domain, with answers of yes, sometimes, or not yet. A yes indicates reaching the achievement with 10 points awarded, a sometimes indicates partial achievement with 5 points awarded, and a not yet indicates not achieved with 0 points awarded. The sum score of each domain was calculated and compared with the cutoff scores reached, which were derived empirically by subtracting 2 standard deviations from the mean for each area of development [41]. A score below the cutoff point indicates a fail on the ASQ. The questionnaires were used to assess the relationship between maternal and infant iodine and selenium status, maternal iron status, and recorded early child neurodevelopment.

\section{Dietary Intake}

To assess participant dietary intake including nutrients that may be associated with mental health and child development including iodine, selenium, and iron intake, participants were asked to complete a weighed 4-day diet diary within 2 weeks of the initial study visit. All 4 days were consecutive and included one weekend day. Each participant was requested to record food items, brands, amount consumed, and the content of the nutritional information panel if applicable. All food and beverage items consumed were weighed and measured with a QM-7288 electronic kitchen scale (Digitech), and household measurement cups and spoons were provided. The Digitech scale can weigh up to 5 kilograms with an accuracy to 1 gram; all women were shown how to use the scale to quantify food items. All participants received both written and oral instructions on how to complete the record, which included a written example of a 1-day food record. Women were also asked to include dietary supplements consumed. When eating or dining out, participants were asked to estimate the portion size of all food eaten. The food record and equipment were collected or return posted 2 weeks after the initial visit.

A 69-item self-administrated semiquantitative iodine- and selenium-specific food frequency questionnaire, adapted from an Australian study of pregnant women [42], was used to estimate habitual maternal iodine and selenium intake at the first and third study visits. An iron-specific food frequency questionnaire, validated by other female population groups in New Zealand, was used to assess women's iron-related dietary patterns [43] at the second study visit. Within 2 weeks of this visit, participants also completed a 3-day estimated food dietary record for their infants to enable assessment of infant nutrient intakes at weaning periods.

All dietary data were entered into Foodworks 9 Professional (Xyris Pty Ltd) online and analyzed using data sets from the New Zealand Foodfiles 2016 to estimate nutrient intake. When food items were not included in Foodfiles 2016, new food items were created based on the information directly provided by participants (ie, food packages) or from appropriate international databases from Australia and the United States. Estimates for iodine concentrations of categories of bread (eg, white, fiber white, fruited, mixed grain) were based on data from the Ministry of Primary Industries [22], since iodine content has not been determined for all commercially made bread in New Zealand after the mandatory fortification of bread with iodized salt. It was difficult to quantify the amount of discretionary salt added to food. However, for women who reported using iodized salt, $48 \mu \mathrm{g}$ of iodine (equivalent to $1 \mathrm{~g}$ of salt) was added to their iodine intakes [21]. Dietary supplements used by participants were entered into Foodworks as a new food item based on nutritional information obtained from the manufacturers. To ensure accuracy and completeness, a registered nutritionist (YJ) checked all dietary data and then transferred the data to SPSS Statistics (IBM Corporation) version 23 for statistical analysis. 


\section{Anthropometry}

Maternal and infant anthropometry measurements were obtained at each study visit. Women's weight was measured using the same annually calibrated weighing scale with a capacity of 150 kilograms (Detecto). Before standing on the scale, participants were asked to remove their shoes and to wear minimum clothes. Body weight was recorded to the nearest 0.1 kilogram. Height was measured by using a Toledo stadiometer and recorded to the nearest millimeter [44]. Maternal body composition was determined using both bioelectrical impedance analysis (InBody230, InBody Co) and air displacement plethysmography (BodPod, COSMED SRL). Measurements were completed under the following conditions: minimal clothing, wearing swimming cap, before midday, after urination, normal room temperature $\left(20^{\circ} \mathrm{C}\right.$ to $\left.25^{\circ} \mathrm{C}\right)$, with no exercise, eating, drinking, or bathing/showering within 2 hours prior to measurement (preferably completing the measurement after breastfeeding the baby). On the day of the test, quality control steps for BodPod were carried out by following the manufacturer's instructions, with acceptance criteria being volume $\pm 100 \mathrm{~mL}$ of actual volume and standard deviation $\leq 75 \mathrm{~mL}$.

Infant recumbent length was measured crown to heel using an infant length board and recorded to the nearest millimeter. Infant weight (without clothing and diapers) was measured using a baby weighing scale (Nagata Scale Co Ltd) and recorded to the nearest 10 grams. Infant head circumference was measured over the most prominent part on the back of the head (occiput) and just above the eyebrows (supraorbital ridges) by using a flexible, nonstretch tape [44] and recorded to the nearest even millimeter.

\section{Ultrasound Measurement of Thyroid Gland Volume}

A portable ultrasound (uSmart 3200T Ultrasound System, Teratech Corp) equipped with a linear transducer ( 7 to $15 \mathrm{mHz}$ ) was used for the thyroid measurement. Women were examined in a supine position (an adequate neck extension was achieved by placing pillows under the shoulders). Longitudinal and transverse scans were performed. Measurements of anteroposterior diameter and width (mediolateral diameter) were obtained with electronic calipers on a transverse image. The maximum lobe length was measured on a longitudinal width. The total volume of each thyroid gland was the sum of the volumes of left and right lobes, excluding the volume of the isthmus but including any nodules and/or cystic areas. The formula used to calculate the volume for each lobe is anteroposterior diameter $\times$ width $\times$ length $\times 0.479$ [45]. A total volume greater than $18 \mathrm{~mL}$ was defined as thyroid enlargement based on the normative thyroid volume in iodine sufficient populations [46]. Any participant with observed abnormalities was referred to clinical health professionals for further assessment.

\section{Biomarker Analysis}

During each study visit, spot urine samples from each participating woman and her infant were collected to assess iodine, selenium, and creatinine excretion. All maternal spot urine samples were collected in the morning and immediately frozen and stored at $-20^{\circ} \mathrm{C}$. Infant urine was collected using a $100 \mathrm{~mL}$ pediatric urine bag placed inside the diaper and checked every 10 minutes. The collected urine was frozen and stored at $-20^{\circ} \mathrm{C}$ for later analysis. Spot urine samples can be used to estimate iodine status of a population but not for individual iodine deficiency diagnosis [47]. It was not possible to estimate dietary iodine and selenium intake for lactating women via urine as we were unable to determine the daily loss of selenium from breast milk. As creatinine output is relatively constant, the adjusted iodine/creatinine ratio ( $\mu$ g iodine per $g$ creatinine) can be used as a proxy measure of iodine excretion [48].

Lactating women were asked to provide a breast milk sample (approximately 30 to $50 \mathrm{~mL}$ ) at each visit using an Allegro electric breast pump (Unimom NZ) if required. All breast milk samples were collected before noon on the study visit day, and timing of breast milk collection was not standardized. Breast milk samples were analyzed for iodine and selenium concentration, allowing for estimations of infant intake of iodine and selenium based on $750 \mathrm{~mL} / \mathrm{d}$ of milk production [49].

Iodine and selenium concentration in both urine and breast milk samples were determined by an accredited commercial laboratory (Hill Laboratories) using inductively coupled plasma mass spectrometry (ICP-MS) [50]. Quality control procedures included analysis of blanks, analytical repeats, and certified reference material to ensure accuracy and precision. The Massey University Nutrition Laboratory measured creatinine using the Jaffe method in a Flexor E (Vital Scientific) biochemistry analyzer.

To assess further selenium status, toenail clippings from women and nail clippings from infants were collected. Toenail clippings have been used to determine selenium concentrations in large cohort or epidemiological studies, such as for the preeclampsia risk in pregnant women [51]. The instruction for sample collection was explained to participants during each study visit and nail clippings were self-collected by participating women at home, with the collected samples brought back by the participants at the following study visit. All toenail clippings were stored at room temperature prior to analysis. Nail clipping samples will be prepared by using the method adapted from nail zinc analysis [52]. This involves washing all nail clipping samples by using 5 minutes contact with $25 \mathrm{~mL}$ portions in the order of acetone, water, acetone, water, and water [53]. Selenium concentration will be measured by ICP-MS.

During the second study visit, to assess blood hemoglobin concentrations, the handheld HemoCue $\mathrm{Hb} 201+$ device (HemoCue America) was used, a standard in hemoglobin point-of-care testing [35,54]. It requires a finger prick and wicking of capillary blood into a pretreated microcuvette for analysis. Quality tests using external, liquid controls were necessary for each day of instrument use prior to sample analysis.

A qualified and experienced phlebotomist collected nonfasting maternal venous blood samples $(22 \mathrm{~mL})$ at the second study visit. Samples were centrifuged and aliquoted into microcentrifuge tubes prelabeled with participant unique sample ID and then stored at $-80^{\circ} \mathrm{C}$. In conjunction with the hemoglobin results, collected maternal venous blood samples were used to determine iron status by measuring soluble transferrin receptors and serum ferritin (using the chemiluminescent microparticle 
immunoassay [CMIA] method), which reflects iron storage, but if serum ferritin levels are increased during infection or inflammation, it may mask any iron deficiency results [55]. Therefore, an inflammatory marker, C-reactive protein, was measured (tested by an immunoturbidometric method analyzed on an Abbott C Series analyzer [Abbott Labs]).

Venous blood samples were assayed for hormonal biomarkers: free T3, free T4, and thyroid stimulating hormone via CMIA method; thyroglobulin (Tg, Beckman Coulter Access method); and antithyroglobulin antibodies (anti-Tg, CMIA method) at
Canterbury Health Laboratories. Serum thyroglobulin has been suggested as an alternative method to assess individual iodine status reflecting a period of months [56]; to avoid potential underestimation of thyroglobulin, anti-Tg and antithyroid peroxidase (anti-TPO) were measured. Selenium status was assessed by determining the biomarker plasma selenium via ICP-MS method [57].

Details of data and biological samples collected from both mothers and infants throughout the study period are summarized in Tables 1 and 2.

Table 1. Summary of outcome measures collected from participating women and their infants.

\begin{tabular}{|c|c|c|c|}
\hline Outcome & Visit 1 & Visit 2 & Visit 3 \\
\hline \multicolumn{4}{|l|}{ Dietary intake } \\
\hline Maternal 4-day dietary diary & $\mathrm{x}$ & & \\
\hline Maternal food frequency questionnaire-iodine/selenium & $\mathrm{x}$ & & $\mathrm{x}$ \\
\hline Maternal food frequency questionnaire-iron & & $\mathrm{x}$ & \\
\hline Infant 3-day dietary diary & & $\mathrm{x}$ & \\
\hline \multicolumn{4}{|l|}{ Anthropometry } \\
\hline Maternal weight and height & $\mathrm{x}$ & $\mathrm{x}$ & $\mathrm{x}$ \\
\hline Maternal body composition via BodPod and BIA ${ }^{\mathrm{a}}$ & $\mathrm{x}$ & $\mathrm{x}$ & $\mathrm{x}$ \\
\hline Infant weight, height, and head circumference & $\mathrm{x}$ & $\mathrm{x}$ & $\mathrm{x}$ \\
\hline \multicolumn{4}{|l|}{ Biochemistry } \\
\hline Maternal spot urine samples & $\mathrm{x}$ & $\mathrm{x}$ & $\mathrm{x}$ \\
\hline Maternal breast milk samples & $\mathrm{x}$ & $\mathrm{x}$ & $\mathrm{x}$ \\
\hline Maternal toenail clipping samples & $\mathrm{x}$ & $\mathrm{x}$ & $\mathrm{x}$ \\
\hline Maternal venous blood samples & & $\mathrm{x}$ & \\
\hline Maternal capillary blood samples & & $\mathrm{x}$ & \\
\hline Infant spot urine samples & $\mathrm{x}$ & $\mathrm{x}$ & $\mathrm{x}$ \\
\hline Infant nail clipping samples & $\mathrm{x}$ & $\mathrm{x}$ & $\mathrm{x}$ \\
\hline \multicolumn{4}{|l|}{ Others } \\
\hline Maternal thyroid gland volume via ultrasound & & $\mathrm{x}$ & \\
\hline Maternal Edinburgh Postnatal Depression Scale results & $\mathrm{x}$ & $\mathrm{x}$ & $\mathrm{x}$ \\
\hline Maternal self-reported health questionnaire & $\mathrm{x}$ & $\mathrm{x}$ & $\mathrm{x}$ \\
\hline Maternal iodine nutritional knowledge questionnaire & $\mathrm{x}$ & & \\
\hline Infant health questionnaire reported by mothers & $\mathrm{x}$ & $\mathrm{x}$ & $\mathrm{x}$ \\
\hline
\end{tabular}

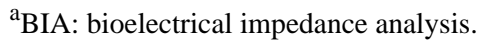


Table 2. Analysis from biological data collected at each study visit for the Mother and Infant Nutrition Investigation study cohort.

\begin{tabular}{|c|c|c|c|c|c|c|}
\hline \multirow[t]{2}{*}{ Samples } & \multicolumn{2}{|l|}{ Visit 1} & \multicolumn{2}{|l|}{ Visit 2} & \multicolumn{2}{|l|}{ Visit 3} \\
\hline & Mothers & Infants & Mothers & Infants & Mothers & Infants \\
\hline \multicolumn{7}{|l|}{ Spot urine } \\
\hline Iodine & $\mathrm{x}$ & $\mathrm{x}$ & $\mathrm{x}$ & $\mathrm{x}$ & $\mathrm{x}$ & $\mathrm{x}$ \\
\hline Selenium & $\mathrm{x}$ & $\mathrm{x}$ & $\mathrm{x}$ & $\mathrm{x}$ & $\mathrm{x}$ & $\mathrm{x}$ \\
\hline Creatinine & $\mathrm{x}$ & & $\mathrm{x}$ & & $\mathrm{x}$ & \\
\hline \multicolumn{7}{|l|}{ Breast milk (if available) } \\
\hline Iodine & $\mathrm{x}$ & & $\mathrm{x}$ & & $\mathrm{x}$ & \\
\hline Selenium & $\mathrm{x}$ & & $\mathrm{x}$ & & $\mathrm{x}$ & \\
\hline \multicolumn{7}{|l|}{ Blood } \\
\hline Iodine status ${ }^{\mathrm{a}}$ & & & $\mathrm{x}$ & & & \\
\hline Selenium status ${ }^{\mathrm{b}}$ & & & $\mathrm{x}$ & & & \\
\hline Iron status ${ }^{\mathrm{c}}$ & & & $\mathrm{x}$ & & & \\
\hline Thyroid function $^{\mathrm{d}}$ & & & $\mathrm{x}$ & & & \\
\hline \multicolumn{7}{|c|}{ Nail clippings for selenium } \\
\hline Toenails & $\mathrm{x}$ & $\mathrm{x}$ & $\mathrm{x}$ & $\mathrm{x}$ & $\mathrm{x}$ & $\mathrm{x}$ \\
\hline Fingernails & & $\mathrm{x}$ & & $\mathrm{x}$ & & $\mathrm{x}$ \\
\hline
\end{tabular}

${ }^{a}$ Iodine status: testing thyroglobulin and antithyroglobulin.

${ }^{\mathrm{b}}$ Selenium status: testing plasma selenium.

${ }^{\mathrm{c}}$ Iron status: testing hemoglobin, serum ferritin, soluble transferrin receptors, and C-reactive protein.

${ }^{\mathrm{d}}$ Thyroid function: testing serum free triiodothyronine, free thyroxine, thyroid stimulating hormone, and antithyroid peroxidase.

\section{Statistical Analysis}

Statistical analysis will be performed using SPSS Statistics version 23. The Shapiro-Wilk test will be used to test for data normality. Nonparametric data will be expressed as median (25th, 75th percentile), and parametric data will be expressed as mean and standard deviation. Bivariate correlations will be tested using the nonparametric Spearman correlation coefficient. Repeated-measures analysis of variance will be used to calculate continuous variables between groups. Nonparametric Mann-Whitney $U$ test (2-tailed) will be used to examine iodine intake and status between supplement users and nonusers. Multiple regression models analysis will be used to determine the associations between iodine, selenium, iron status, and thyroid function, as well as considering confounding factors. Multivariate analysis will be used to examine possible associations between women's selenium status, thyroid function, and postnatal depression and infant first year neurodevelopment.

\section{Results}

Recruitment traversed the 19-month period between June 2016 and December 2017, and a sample of 91 women-infant pairs was enrolled (Figure 1). Data collection has been completed. Biological samples analysis, excluding nail clippings, is complete. Data analysis and presentation of the results will be available after 2020 . 
Figure 1. Flow chart showing recruitment for the Mother and Infant Nutrition Investigation study.

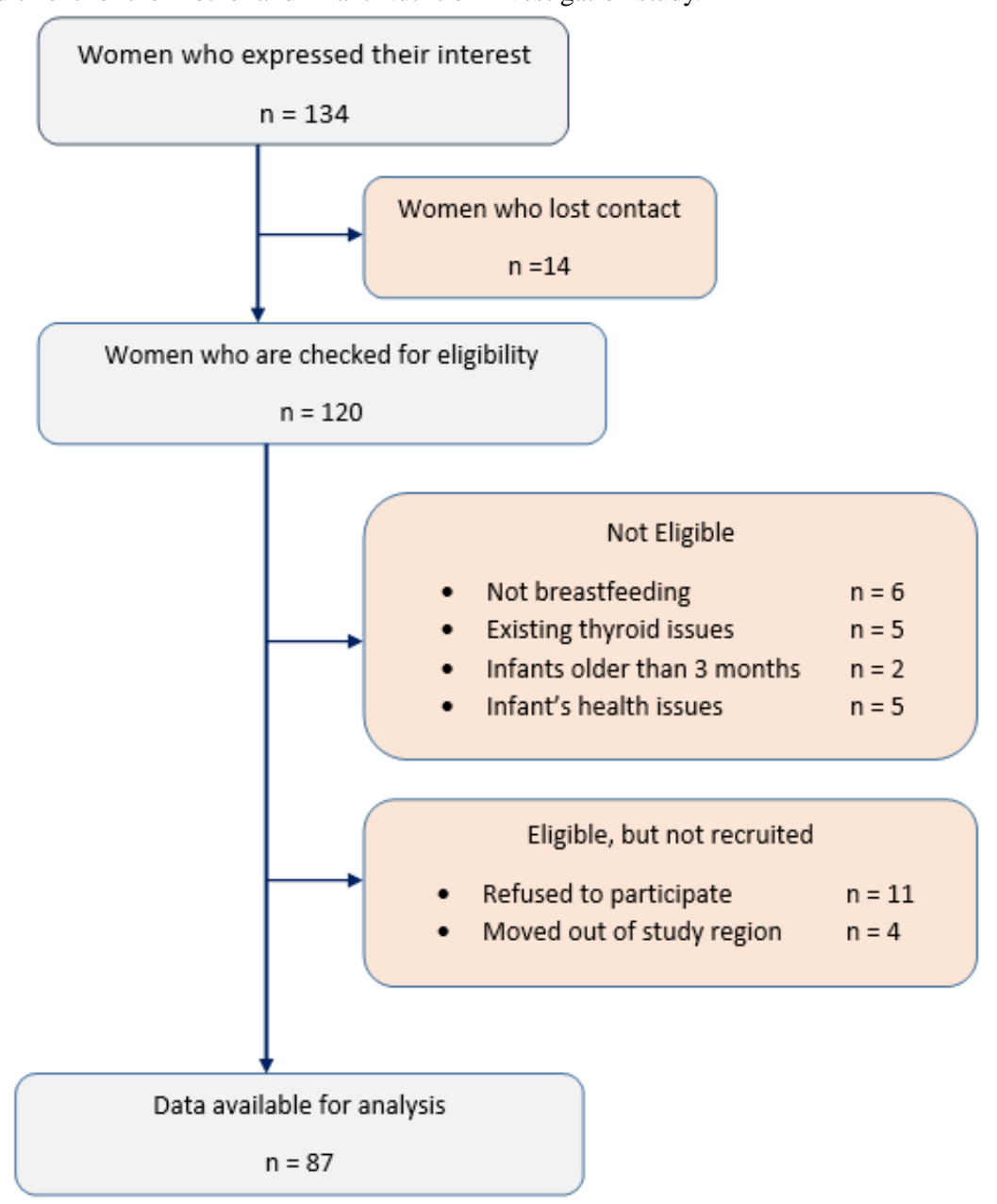

\section{Discussion}

\section{Summary}

A unique aspect of this study is that it will investigate all three micronutrients responsible for adequate thyroid hormone synthesis concurrently, rather than each separately in isolation. This observational longitudinal cohort study will measure the iodine and selenium status of women repeatedly in their first year after birth, which provides an evaluation of their nutritional status. Iodine status among supplement users and nonusers will provide up-to-date data on this postpartum group in New Zealand around 8 years after government interventions. Results will explore whether maternal iodine and selenium status could be used as a proxy measure of infant status. It provides an opportunity to examine the association of maternal iodine and selenium with infant neurodevelopment during their first year. This study explores selenium status using both short-term and long-term measures in relation to neurodevelopment at 6 months and 12 months of age, which has not been reported previously. Furthermore, the study results will add preliminary data on iron status of women at 6 months postpartum.
Importantly, the study will investigate overall thyroid function of women at 6 months postpartum with respect to the risk of postnatal depression. Measurement of thyroid hormones, thyroid stimulating hormone, anti-TPO, $\mathrm{Tg}$, and anti-Tg in serum as well as measuring thyroid gland volume via ultrasound will provide an overall picture of maternal thyroid function after giving birth. This is an opportune time to check thyroid status, especially as women with limited thyroidal reserve or iodine deficiency in pregnancy may develop postpartum thyroid dysfunction, one of the most common endocrine disorders women experience [6,58].

Additionally, there will be longitudinal assessment of mothers' mental health via repeated screening by using the EPDS. The results may add to the literature in postpartum mental health status. Their offsprings' growth and neurodevelopment will be followed during the first year after birth. The findings from this study have the potential to inform future public health policy and practice regarding postpartum women's nutritional status and mental health together with infant health outcomes.

\section{Acknowledgments}

We thank the MINI team, including Anne Broomfield for her technical support, Stephen Mackintosh (sonographer) regarding the extensive ultrasound training in measuring thyroid volume, and Rose Allen from Across Social Service regarding the support for women who were at risk of postnatal depression. In addition, we thank Dr Kathryn Beck for sharing the iron- specific food 
frequency questionnaire. We would like to thank the women and their infants who volunteered for this study. The study was funded by Massey University Research Fund, School of Food and Advanced Technology Postgraduate Fund. The funding bodies played no role in the design of the study and collection, analysis, and interpretation of data or in the writing of the manuscript.

\section{Authors' Contributions}

YJ, LB, and JC conceived and designed the study and acquired funding. SJZH, SS, and RP peer-reviewed the study design. YJ drafted and wrote the manuscript. LB, JC, SJZH, SS, CB, NK, and RP critically reviewed and approved the final manuscript.

\section{Conflicts of Interest}

None declared.

\section{Multimedia Appendix 1}

Flow chart showing stages of Mother and Infant Nutrition Investigation study.

[PNG File, 52 KB-Multimedia Appendix 1]

\section{References}

1. Sylvén SM, Elenis E, Michelakos T, Larsson A, Olovsson M, Poromaa IS, et al. Thyroid function tests at delivery and risk for postpartum depressive symptoms. Psychoneuroendocrinology 2013 Jul;38(7):1007-1013. [doi:

10.1016/j.psyneuen.2012.10.004] [Medline: 23137714]

2. Bauer M, Goetz T, Glenn T, Whybrow PC. The thyroid-brain interaction in thyroid disorders and mood disorders. $\mathrm{J}$ Neuroendocrinol 2008 Oct;20(10):1101-1114 [FREE Full text] [doi: 10.1111/j.1365-2826.2008.01774.x] [Medline: 18673409]

3. Zimmermann MB. The role of iodine in human growth and development. Semin Cell Dev Biol 2011 Aug;22(6):645-652. [doi: 10.1016/j.semcdb.2011.07.009] [Medline: 21802524]

4. Schomburg L, Köhrle J. On the importance of selenium and iodine metabolism for thyroid hormone biosynthesis and human health. Mol Nutr Food Res 2008 Nov;52(11):1235-1246. [doi: 10.1002/mnfr.200700465] [Medline: 18686295]

5. Zimmermann MB, Köhrle J. The impact of iron and selenium deficiencies on iodine and thyroid metabolism: biochemistry and relevance to public health. Thyroid 2002 Oct;12(10):867-878. [doi: 10.1089/105072502761016494] [Medline: 12487769]

6. Stuckey BGA, Kent GN, Allen JR, Ward LC, Brown SJ, Walsh JP. Low urinary iodine postpartum is associated with hypothyroid postpartum thyroid dysfunction and predicts long-term hypothyroidism. Clin Endocrinol (Oxf) 2011 May;74(5):631-635. [doi: 10.1111/j.1365-2265.2011.03978.x] [Medline: 21470286]

7. Le Donne M, Mento C, Settineri S, Antonelli A, Benvenga S. Postpartum mood disorders and thyroid autoimmunity. Front Endocrinol 2017 May 04;8:4-9. [doi: 10.3389/fendo.2017.00091]

8. Shukri NH, Coad J, Weber J, Jin Y, Brough L. Iodine and selenium intake in a sample of women of childbearing age in Palmerston North, New Zealand after mandatory fortification of bread with iodised salt. Food Nutr Sci 2014;05(04):382-389. [doi: $10.4236 /$ fns.2014.54046]

9. Brough L, Gunn C, Weber J, Coad J, Jin Y, Thomson J, et al. Iodine and selenium intakes of postmenopausal women in New Zealand. Nutrients 2017 Mar 09;9(254):1-10 [FREE Full text] [doi: 10.3390/nu9030254] [Medline: 28282932]

10. A portrait of health: key results of the 2006/07 New Zealand Health Survey. Ministry of Health. 2006. URL: https://www. moh.govt.nz/NoteBook/nbbooks.nsf/0/9FF50018D90C43D3CC2574640009AE76/\$file/portrait-of-health-june08.pdf [accessed 2020-07-31]

11. Gibbons V, Conaglen JV, Lillis S, Naras V, Lawrenson R. Epidemiology of thyroid disease in Hamilton (New Zealand) general practice. Aust New Zeal Public Heal 2008;32:421-423. [doi: 10.1111/j.1753-6405.2008.00273.x]

12. Thomson BM, Vannoort RW, Haslemore RM. Dietary exposure and trends of exposure to nutrient elements iodine, iron, selenium and sodium from the 2003-4 New Zealand Total Diet Survey. Br J Nutr 2008 Mar;99(3):614-625. [doi:

10.1017/S0007114507812001] [Medline: 17925056]

13. A focus on nutrition: key findings of the 2008/09 New Zealand Adult Nutrition Survey. URL: https://www.health.govt.nz/ system/files/documents/publications/a-focus-on-nutrition-v2.pdf [accessed 2020-08-01]

14. Bath SC, Rayman MP. Iodine deficiency in the UK: an overlooked cause of impaired neurodevelopment? Proc Nutr Soc 2013 Apr 10;72(2):226-235. [doi: 10.1017/s0029665113001006] [Medline: 23570907]

15. Thomson CD, Colls AJ, Conaglen JV, Macormack M, Stiles M, Mann J. Iodine status of New Zealand residents as assessed by urinary iodide excretion and thyroid hormones. Br J Nutr 1997 Dec;78(6):901-912. [doi: 10.1079/bjn19970208] [Medline: 9497442]

16. Pettigrew-Porter A, Skeaff S, Gray A, Thomson C, Croxson M. Are pregnant women in New Zealand iodine deficient? A cross-sectional survey. Aust N Z J Obstet Gynaecol 2011 Oct;51(5):464-467. [doi: 10.1111/j.1479-828X.2011.01331.x] [Medline: 21875425] 
17. Mulrine HM, Skeaff SA, Ferguson EL, Gray AR, Valeix P. Breast-milk iodine concentration declines over the first 6 mo postpartum in iodine-deficient women. Am J Clin Nutr 2010 Oct;92(4):849-856. [doi: 10.3945/ajcn.2010.29630] [Medline: 20702609]

18. Skeaff S, Thomson C, Gibson R. Mild iodine deficiency in a sample of New Zealand schoolchildren. Eur J Clin Nutr 2002 Dec;56(12):1169-1175 [FREE Full text] [doi: 10.1038/sj.ejcn.1601468] [Medline: 12494301]

19. Skeaff SA, Ferguson EL, McKenzie JE, Valeix P, Gibson RS, Thomson CD. Are breast-fed infants and toddlers in New Zealand at risk of iodine deficiency? Nutrition 2005 Mar;21(3):325-331. [doi: 10.1016/j.nut.2004.07.004] [Medline: 15797674]

20. Folic acid and spina bifida/iodine and iodine deficiency. New Zealand Ministry of Health. URL: https://www.healthed.govt.nz/ system/files/resource-files/HE4147_Folic\%20acid\%20and\%20iodine.pdf [accessed 2020-08-05]

21. Edmonds JC, McLean RM, Williams SM, Skeaff SA. Urinary iodine concentration of New Zealand adults improves with mandatory fortification of bread with iodised salt but not to predicted levels. Eur J Nutr 2016 Apr;55(3):1201-1212. [doi: 10.1007/s00394-015-0933-y] [Medline: 26018655]

22. Mandatory folic acid and iodine fortification in Australia and New Zealand: supplement to the baseline report for monitoring. Australian Institute of Health and Welfare. URL: https://www.aihw.gov.au/getmedia/ 5bd11641-6fb0-4fd3-a509-3b35fe3253b7/13526.pdf.aspx?inline=true [accessed 2020-08-05]

23. Jones E, McLean R, Davies B, Hawkins R, Meiklejohn E, Ma Z, et al. Adequate iodine status in New Zealand school children post-fortification of bread with iodised salt. Nutrients 2016 May 16;298:1-9. [doi: 10.3390/nu8050298]

24. Brough L, Jin Y, Shukri NH, Wharemate ZR, Weber JL, Coad J. Iodine intake and status during pregnancy and lactation before and after government initiatives to improve iodine status, in Palmerston North, New Zealand: a pilot study. Matern Child Nutr 2015 Oct;11(4):646-655 [FREE Full text] [doi: 10.1111/mcn.12055] [Medline: 23782592]

25. Thomson CD, McLachlan SK, Parnell WR, Wilson N, Wohlers M, Scragg R, et al. Serum selenium concentrations and dietary selenium intake of New Zealand children aged 5-14 years. Br J Nutr 2007 Feb;97(2):357-364. [doi: 10.1017/S0007114507336738] [Medline: 17298706]

26. Morris ME, Aguilera A. Mobile, social, and wearable computing and the evolution of psychological practice. Prof Psychol Res Pr 2012 Dec;43(6):622-626 [FREE Full text] [doi: 10.1037/a0029041] [Medline: 25587207]

27. Thomson C, Packer M, Butler J, Duffield A, O'Donaghue K, Whanger P. Urinary selenium and iodine during pregnancy and lactation. J Trace Elem Med Biol 2001 Apr;14(4):210-217. [doi: 10.1016/S0946-672X(01)80004-3] [Medline: 11396779]

28. Jin Y, Coad J, Weber JL, Thomson JS, Brough L. Selenium intake in iodine-deficient pregnant and breastfeeding women in New Zealand. Nutrients 2019 Jan 01;11(1):69 [FREE Full text] [doi: 10.3390/nu11010069] [Medline: 30609662]

29. Barroso F, Allard S, Kahan BC, Connolly C, Smethurst H, Choo L, et al. Prevalence of maternal anaemia and its predictors: a multi-centre study. Eur J Obstet Gynecol Reprod Biol 2011 Nov;159(1):99-105. [doi: 10.1016/j.ejogrb.2011.07.041] [Medline: 21890259]

30. Bodnar LM, Cogswell ME, McDonald T. Have we forgotten the significance of postpartum iron deficiency? Am J Obstet Gynecol 2005 Jul;193(1):36-44. [doi: 10.1016/j.ajog.2004.12.009]

31. Calje E, Skinner J. The challenge of defining and treating anemia and iron deficiency in pregnancy: a study of New Zealand midwives' management of iron status in pregnancy and the postpartum period. Birth 2017 Jun;44(2):181-190. [doi: 10.1111/birt.12282] [Medline: 28233929]

32. Conner TS, Richardson AC, Miller JC. Optimal serum selenium concentrations are associated with lower depressive symptoms and negative mood among young adults. J Nutr 2015 Jan;145(1):59-65. [doi: 10.3945/jn.114.198010] [Medline: 25378685]

33. Mokhber N, Namjoo M, Tara F, Boskabadi H, Rayman MP, Ghayour-Mobarhan M, et al. Effect of supplementation with selenium on postpartum depression: a randomized double-blind placebo-controlled trial. J Matern Fetal Neonatal Med 2011 Jan;24(1):104-108. [doi: 10.3109/14767058.2010.482598] [Medline: 20528216]

34. Thio IM, Oakley Browne MA, Coverdale JH, Argyle N. Postnatal depressive symptoms go largely untreated: a probability study in urban New Zealand. Soc Psychiatry Psychiatr Epidemiol 2006 Oct;41(10):814-818. [doi:

10.1007/s00127-006-0095-6] [Medline: 16838090 ]

35. Deverick Z, Guiney H. Postnatal depression in New Zealand: findings from the 2015 New Mothers' Mental Health Survey. 2016. URL: https://www.hpa.org.nz/sites/default/files/\%EF\%BF\%BCPostnatal\%20Depression\%20in\%20New\%20Zealand -\%20Findings \%20from\%20the\%202015\%20New\%20Mothers\%E2\%80\%99\%20Mental\%20Health\%20Survey.pdf [accessed 2020-08-05]

36. Campbell S, Norris S, Standfield L, Suebwongpat A. Screening for postnatal depression within the Well Child Tamariki Ora framework. 2008. URL: http://www.healthsac.net/downloads/publications/HSAC01\%20PND\%20170608\%20Final. pdf [accessed 2020-08-05]

37. Murray L, Fiori-Cowley A, Hooper R, Cooper P. The impact of postnatal depression and associated adversity on early mother-infant interactions and later infant outcome. Child Dev 1996 Oct;67(5):2512-2526. [Medline: 9022253]

38. Groer MW, Morgan K. Immune, health and endocrine characteristics of depressed postpartum mothers. Psychoneuroendocrinology 2007 Feb;32(2):133-139. [doi: 10.1016/j.psyneuen.2006.11.007] [Medline: 17207585] 
39. Cox JL, Holden JM, Sagovsky R. Detection of postnatal depression: development of the 10-item Edinburgh Postnatal Depression Scale. Br J Psychiatry 1987 Jun;150:782-786. [doi: 10.1192/bjp.150.6.782] [Medline: 3651732]

40. Matthey S. Using the Edinburgh Postnatal Depression Scale to screen for anxiety disorders. Depress Anxiety 2008;25(11):926-931. [doi: 10.1002/da.20415] [Medline: 18041072]

41. Squires J, Bricker D. Ages \& Stages Questionnaires: A Parent-Completed Child Monitoring System. Third Edition. Baltimore: Paul H. Brookes Publishing Co; 2009.

42. Condo D, Makrides M, Skeaff S, Zhou SJ. Development and validation of an iodine-specific FFQ to estimate iodine intake in Australian pregnant women. Br J Nutr 2015 Mar 28;113(6):944-952. [doi: 10.1017/S0007114515000197] [Medline: 257444430]

43. Beck KL, Kruger R, Conlon CA, Heath AM, Coad J, Matthys C, et al. The relative validity and reproducibility of an iron food frequency questionnaire for identifying iron-related dietary patterns in young women. J Acad Nutr Diet 2012 Aug;112(8):1177-1187. [doi: 10.1016/j.jand.2012.05.012] [Medline: 22818726]

44. Rosalind G. Principles of Nutritional Assessment. Oxford: Oxford University Press; 1990.

45. Brunn J, Block U, Ruf G, Bos I, Kunze WP, Scriba PC. [Volumetric analysis of thyroid lobes by real-time ultrasound (author's transl)]. Dtsch Med Wochenschr 1981 Oct 09;106(41):1338-1340. [doi: 10.1055/s-2008-1070506] [Medline: 7274082]

46. Indicators for assessing iodine deficiency disorders and their control programme. URL: http://whqlibdoc.who.int/hq/1993/ WHO NUT 93.1.pdf?ua=1\&ua=1 [accessed 2020-08-05]

47. Thomson C, Smith T, Butler K, Packer M. An evaluation of urinary measures of iodine and selenium status. J Trace Elem Med Biol 1996 Dec;10(4):214-222. [doi: 10.1016/S0946-672X(96)80038-1] [Medline: 9021672]

48. Zimmermann MB. Methods to assess iron and iodine status. Br J Nutr 2008 Jun;99 Suppl 3:S2-S9. [doi: 10.1017/S000711450800679X] [Medline: 18598585]

49. Neville MC, Keller R, Seacat J, Lutes V, Neifert M, Casey C, et al. Studies in human lactation: milk volumes in lactating women during the onset of lactation and full lactation. Am J Clin Nutr 1988 Dec;48(6):1375-1386. [doi: 10.1093/ajcn/48.6.1375] [Medline: 3202087]

50. Fecher PA, Goldmann I, Nagengast A. Determination of iodine in food samples by inductively coupled plasma mass spectrometry after alkaline extraction. J Analyt Atom Spectrom 1998;13(9):977-982. [doi: 10.1039/a801671b]

51. Rayman MP, Bode P, Redman CW. Low selenium status is associated with the occurrence of the pregnancy disease preeclampsia in women from the United Kingdom. Am J Obstet Gynecol 2003 Nov;189(5):1343-1349. [doi: 10.1067/s0002-9378(03)00723-3] [Medline: 14634566]

52. International Zinc Nutrition Consultative Group Technical Brief. URL: https://static1.squarespace.com/static/ 56424f6ce4b0552eb7fdc4e8/t/5c1abb0870a6adf8eb61d85b/1545255689912/IZiNCG Technical+Brief+\%239 final.pdf [accessed 2020-08-05]

53. Gherase MR, Desouza ED, Farquharson MJ, McNeill FE, Kim C, Fleming DEB. X-ray fluorescence measurements of arsenic micro-distribution in human nail clippings using synchrotron radiation. Physiol Meas 2013 Aug 23;34(9):1163-1177. [doi: 10.1088/0967-3334/34/9/1163]

54. Parker M, Han Z, Abu-Haydar E, Matsiko E, Iyakaremye D, Tuyisenge L, et al. An evaluation of hemoglobin measurement tools and their accuracy and reliability when screening for child anemia in Rwanda: a randomized study. PLoS One 2018;13(1):e0187663 [FREE Full text] [doi: 10.1371/journal.pone.0187663] [Medline: 29300737]

55. Coad J, Pedley K. Iron deficiency and iron deficiency anemia in women. Scand J Clin Lab Investig 2014 Aug;74(sup244):82-89. [doi: 10.3109/00365513.2014.936694]

56. Ma ZF, Skeaff SA. Thyroglobulin as a biomarker of iodine deficiency: a review. Thyroid 2014 Aug;24(8):1195-1209 [FREE Full text] [doi: 10.1089/thy.2014.0052] [Medline: 24762031]

57. Ashton K, Hooper L, Harvey L, Hurst R, Casgrain A, Fairweather-Tait S. Methods of assessment of selenium status in humans: a systematic review. Am J Clin Nutr 2009 Jun;89(6):2025S-2039S. [doi: 10.3945/ajcn.2009.27230F] [Medline: 19420095]

58. Knudsen N, Jorgensen T, Rasmussen S, Christiansen E, Perrild H. The prevalence of thyroid dysfunction in a population with borderline iodine deficiency. Clin Endocrinol Oxf 1999 Sep;51(3):361-367. [doi: 10.1046/j.1365-2265.1999.00816.x]

\section{Abbreviations}

Anti-Tg: antithyroglobulin antibodies

Anti-TPO: antithyroid peroxidase

ASQ: Ages and Stages Questionnaire

CMIA: chemiluminescent microparticle immunoassay

EPDS: Edinburgh Postnatal Depression Scale

ICP-MS: inductively coupled plasma mass spectrometry

MINI: Mother and Infant Nutrition Investigation

T3: triiodothyronine 
T4: thyroxine

Tg: thyroglobulin

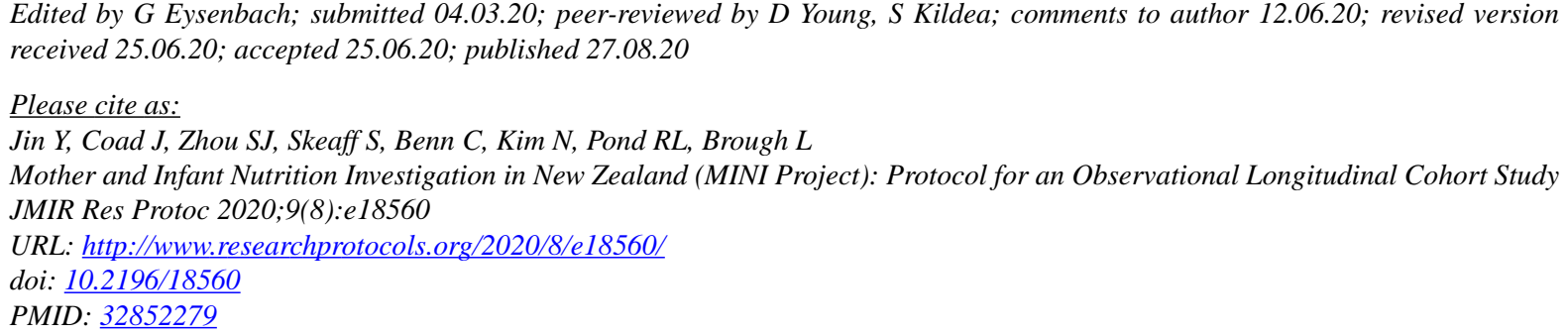

(C) Ying Jin, Jane Coad, Shao J Zhou, Sheila Skeaff, Cheryl Benn, Nicholas Kim, Rachael L Pond, Louise Brough. Originally published in JMIR Research Protocols (http://www.researchprotocols.org), 27.08.2020. This is an open-access article distributed under the terms of the Creative Commons Attribution License (https://creativecommons.org/licenses/by/4.0/), which permits unrestricted use, distribution, and reproduction in any medium, provided the original work, first published in JMIR Research Protocols, is properly cited. The complete bibliographic information, a link to the original publication on http://www.researchprotocols.org, as well as this copyright and license information must be included. 